\title{
Trend of Research and Development of Track Technology
}

\author{
Hideyuki TAKAI \\ General Manager, Track Technology Div.
}

\begin{abstract}
The Railway Technical Research Institute has adopted four items as the goal of the research and development until fiscal 2004. It aims at the realization of a "High reliability railway," "Low cost railway," "Attractive railway" and "Railway compatible with the environment." This paper introduces the research and development activities of track technology corresponding to these four items. They include prevention of flange-climb derailment and rail defect, track inspection technology and track maintenance planning system, speed-up and improvement of riding quality, reducing $\mathrm{CO}_{2}$ discharge and recycle of track materials.
\end{abstract}

Keywords : track technology, research and development, running safety, economic efficiency, comfortableness, environmental harmony

\section{Introduction}

The structure of railway tracks that consist of two rails fixed with ties at a certain distance basically has not changed since the railway made its debut. It is a very long linear structure laid outdoors, and sometimes subjected to disaster. Therefore, the track structure has high flexibility to ensure prompt restoration, though it seems very weak at a glance. Nevertheless, tracks have been improved to keep pace with the improvement of railway such as extension, speedup and high-density operation of vehicles.

The Railway Technical Research Institute (RTRI) adopted a basic plan at the beginning of fiscal 2000 and set the following four items as the goal of research and development ${ }^{1}$. See Fig. 1.

a. High reliability railway (safety, stability)

b. Low cost railway (economical efficiency)

c. Attractive railway (speediness, convenience, comfort)

d. Railway compatible with the environment (harmony with environment)

Those four items are closely related with one another. It is not easy to explain the relation between these items, but we explain recent research and development activities of track technology by replacing "railway" with "track." Due to the limited space of this paper, The auther describe mainly the fields drawing attention in Japan and foreign countries. As a general guide to Japanese railway technologies, "Japanese Railway Technology Today" was published in December 20012).

\section{Highly reliable track (safety, stability)}

\subsection{Countermeasures for flange-climb derailment on tight curves at low speed.}

The derailment and collision accident that occurred at the Nakameguro station on the Hibiya line, Tokyo Metropolitan Subways, in March 2000, was noteworthy in the history of railway accidents for its seriousness and



Fig. 1 Goal of the research and development on railways

special features of the damage. The Accident Investigation Committee, Ministry of Transportation, established on the same day, investigated the accident and performed a repetition test by a trainset of the same type. The final report was issued by the Committee in October 2000.

This derailment was classified as the type of "flange climb derailment on tight curve at low speed." The final report proposed an "Estimated derailment coefficient ratio" to estimate the margin for flange-climb derailment as an urgent countermeasure ${ }^{3)}$. At present, we promote a general research including a real-scale running test at RTRI to investigate the mechanism of flange climb derailment, and propose a design / maintenance standard of track and vehicle. Figure 2 shows an image of the design of track / vehicle to consider running safety.

\subsection{Rail defect prevention}

The Derailment accident occurred in Hatfield, the UK in October 2000, and TGV derailment in France at the speed of $130 \mathrm{~km} / \mathrm{h}$ in October 2001 are also presumed to have been caused by the result of rail breakage. Therefore, in Europe and the US, interest is rising in the rolling contact fatigue between wheel and rail. Eleven papers were presented regarding this problem at the World Conference on Railway Research (WCRR) that was held 




Fig. 2 Design of track and vehicle to consider running safety

in Cologne, Germany, in November 2001. It is the evidence of the height of the interest and urgentness ${ }^{4)}$.

We study the bainite rails, as a prevention measure of rail shelling that is the most important factor of rail defect. As the rails are easier to wear than normal rails, the rolling fatigue layer that becomes the cause of shelling is difficult to increase. At present, these are in the field test on commercial lines for the durability of rail in general welding sections. We also research the influence of wear and lubrication between wheel and rail on the cohesion characteristic and dynamic action ${ }^{5)}$.

The rail welding technology is considered to become increasingly important from now on. The accumulation of the defect cases is extremely important to improve rail welding technology. Fortunately, all welding defect rails on JR lines are sent to RTRI for analysis and investigation.

Even though long welded rails (LWR) become more popular, jointed rails will still be in use. We are studying the mechanism and service life of rail joints ${ }^{6}$.

\subsection{Track layout in curves}

Track layouts in curves are designed according to the vehicle structure and operational conditions. Because the life of the railway infrastructure is very long, it is extremely difficult to change existing railway tracks. Therefore, conditions of the total railway system may become imbalance in some cases, according to the enlargement of vehicle size and speed-up. This means a decrease in the margin for safety.

A new ministerial ordinance of engineering standard of railway was put in force in March 2002. It is a Ministerial ordinance to revise the former standards from the viewpoint of performance standardization and barrier-free structures for mobility-handicapped people. To study the standard, the "Committee for studying track layout on curves" was organized in 1998. The committee worked actively from fiscal 1998 to 2001 and the results of discussions were adopted in the standard.

\section{Low cost track (economical efficiency)}

\subsection{Track deterioration characteristics}

The track ballast resistance is gained from the contact between each ballast particle. To quantitatively analyze the deformation characteristics of ballast bed as a collection of ballast particles, we adopt a method of discontinuous deformation analysis (DDA). We are now at the stage of feasibility study according to the test results of real-scale ballast deformation test.

Characteristics of ballast, one of the most important components of ballasted track, are distinguished by quality, shape and size distribution of stones. Our recent study is on the wear characteristics of the ballast under repetitive trainloads, and its effect on the track subsidence.

We are also developing a method to strengthen ballast beds, which makes a realistic solution of track deterioration ${ }^{7}$.

In regard to the estimation of track irregularity growth, the most popular method has been to trace sequential track irregularity data and find some pattern in it. A new method is to perform computer simulation by using a track dynamic model. This method makes it possible to clarify the influence of initial track irregularity on the irregularity growth.

\subsection{Track measuring technology}

A second stage high-speed track measuring car "New doctor yellow" of Central Japan Railway Company was put in use followed by "East i" of East Japan Railway. These two track-measuring cars adopt a "two-bogie system" that has been developed for 10 years by RTRI. These systems solve the problem of speed restriction of conventional track measuring car with three bogies, and make it possible to measure at the same speed as that of commercial trains. It is an epoch-making technology development in the field of track measuring.

On the other hand, we are also developing an "inertia-code method" track measuring system ${ }^{8}$. This system aims both at the easiness of inertia method and at the simplicity of mid-cord method. We are now testing a prototype, and planning to install it on track maintenance vehicles or commercial vehicles in the near future.

\subsection{Support system for track maintenance planning}

To make track maintenance work more efficient, research and development on a support system for track maintenance planning is under way, for example by using the genetic algorithm $(\mathrm{GA})^{9}$ ). Similar systems are developed all over the world. One of the famous systems is the ECOTRACK of Europe Railway Research Institute (ERRI). A number of European railways use the system tentatively to evaluate its performance in practical use.

The European Union (EU) decided the independency of railway operation from the governments, separation of infrastructure from operation, rights to use the infrastructure for international traffic (open access) in the command issued by the EU Minister Board (91/440/EEC,1991). Infrastructure companies need to set proper rates because 
operation companies use the railway tracks and pay for it. The support system for track maintenance planning in Europe has been developed to respond to such necessity. Basically, these systems estimate track deterioration and decide a maintenance plan by numerous algorithms on the basis of experience.

\section{Attractive track (speediness, convenience, comfort)}

\section{1 speed improvement}

Unfortunately, we cannot clarify whether the general term "Attractive track" exists among railway users. However, to achieve speediness, convenience and comfort, improvement of the track technology is indispensable. In particular, train speed-up and improvement riding quality are important.

The speed of $350 \mathrm{~km} / \mathrm{h}$ has already become a global standard for designed maximum speed of high-speed railways. In Japan, series 700 shinkansen vehicles of West Japan Railway (JR West) has achieved $300 \mathrm{~km} / \mathrm{h}$ commercial operations on the Sanyo Shinkansen line. It was originally designed for $260 \mathrm{~km} / \mathrm{h}$, then the small curve radius is now one of the reasons for speed restriction. The solution of the problem of environmental pollutions (noise or vibration) is a premise for train speed-up.

In the case of conventional lines (narrow-gauge lines), all JR companies adopt a tilting train system. By this means, speed-up on curves reached the first stage. RTRI started a comprehensive study to develop a new generation tilting train called the "High speed curving vehicle (HSCV)" which promoted speed-up further with a technology of super low gravity center and an intelligent control system.

\subsection{Improvement of riding quality}

To discuss riding quality, the definition of "riding quality" is the first object. Regarding this subject, the International Organization for Standardization (ISO) acts aggressively, and already published some standards. In Japan, we normally estimate riding quality by the "Riding quality index" that was proposed by former Japanese National Railways (JNR) or the "Riding quality level." Of course, the proposal of ISO standards does not obstruct the effectiveness of existing standards, it gives an influence on the international comparison tool of riding quality or requirements for export of railway vehicles.

The recent improvement of riding quality of Shinkansen trains is remarkable. One of the reasons is the introduction of newly developed trainsets. The other and more effective reason is the improvement of the method to correct long wavelength track irregularities. This improvement is more obvious with the ballasted track sections than ballastless track sections, as ballasted tracks are advantageous in the repair of track alignment. A future study to confirm the experiential theory of "good track conditions ensure durability" is the key to the improvement not only of riding quality but also for cost reduction. As the riding quality is means for relative evaluation of the sections where trains run, there are no limits with respect to satisfaction. There may be a solution of "track maintenance by considering comfortable train vibration."

\section{The railways compatible with the environment (harmony with environment)}

\subsection{Noise and vibration prevention}

A new solid-bed track with removable resilient ties (STR-D) was developed as a low noise and low vibration track for Shinkansen ${ }^{10)}$. It has become popular for its characteristics not only of the effectiveness of the reduction of noise and vibration but also of the convenience for exchanging resilient materials. In addition, application for $50 \mathrm{kgN}$ rails becomes possible due to the development of new rail fastening device.

On the other hand, to reduce wheel-rolling noise that is one of the major elements of railway noise, we are studying the relation between the rolling noise of wheel and the rail surface roughness.

\subsection{Environmental preservation}

Generally, it is said that railways are an environmentfriendly transportation system. The proportion of $\mathrm{CO}_{2}$ discharge from transportation facilities is $22 \%$ in Japan. Of this volume of $\mathrm{CO}_{2}$ discharge, automobiles account for $88 \%$; marine transportation $5 \%$; aviation $4 \%$ and railway $3 \%$ (1998). Therefore, even if railways make efforts to reduce $\mathrm{CO}_{2}$ discharge, the contribution to the reduction of the total $\mathrm{CO}_{2}$ discharge will be small. However, if passengers and freights shift to railways from other transportation facilities, because of the improvement of convenience or cost reduction of railways, the contribution will become very large.

In the field of track engineering, there are some examples of recycle materials like "ballast mats" that are a recycled product of used rubber automobile tires. But these were for the purpose of cost reduction. Recently, research and development have been done with respect to the environment, for example ballast made by incinerated ash or noise absorption components produced from recycled materials.

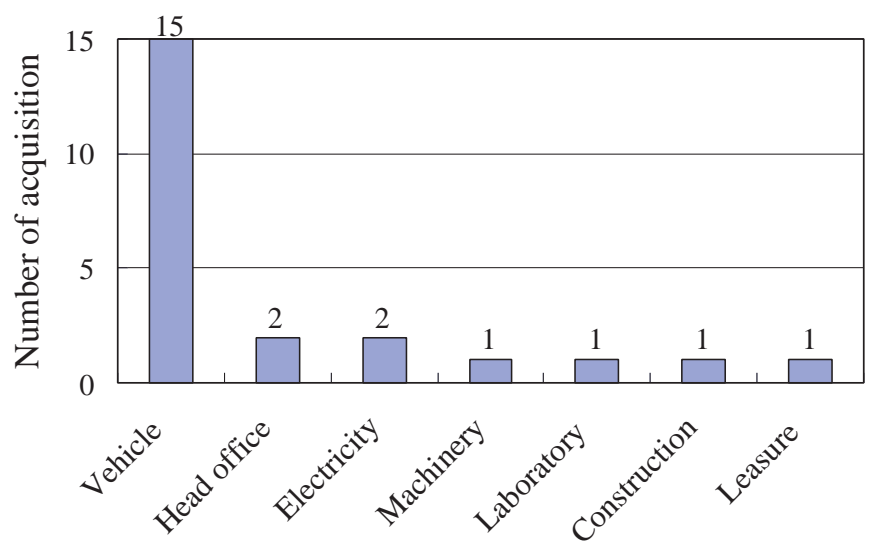

Fig. 3 Number of ISO 14001 acquisition in railway industry 
As for the environmental management system (ISO14001), the first certification was granted for a railway company in January 1999. There are 23 cases of acquisition as of March 2001 (Fig. 3) $^{11)}$.

\section{Conclusions}

Track technology is a technology specific to railways. We feel proud of the fact that the RTRI contributes considerably to the development of this technology. However, the recent trend of borderless and global development of technology show that the pride will lose its base instantly unless there is self-effort or improvement. Fortunately, RTRI is a non-profitable organization that has a technology-oriented constitution by nature. We intend to promote research and development to raise the status of railway by accepting the sense of values of railway companies, such as a needs-oriented or mission-oriented mind.

\section{References}

1) Kumagai N.: "Research and Development for the Future of Railways in the RTRI Fundamental Plan," QR of RTRI, Vol.42, No. 4, 2001.

2) "Japanese Railway Technology Today," Railway Tech- nical Research Institute \& East Japan Railway Culture Foundation, Dec. 2001.

3) Takai, H.: "Derailment Safety Evaluation by Analytic Equations," QR of RTRI, Vol. 43, No. 3, 2002.

4) Proceedings of the World Congress on Railway Research, Jan. 2002. (CD-ROM)

5) Ishida, M.: "Influence of Gauge Face Worn Profile and Lubrication on Vehicle / Track Interaction," QR of RTRI, Vol. 43, No. 3, Sep. 2002.

6) Kataoka, H., Abe, N., WAKATSUKI, O.: "Evaluation of Service Life of Jointed Rails," QR of RTRI, Vol. 43, No. 3, 2002.

7) Momoya, N.: "Development of Solid Bed Track on Asphalt Pavement," QR of RTRI, Vol. 43, No. 3, 2002.

8) Yazawa, E., Takeshita, K.: "Development of Measurement Device of Track Irregularity using Inertial Midchord Offset Method", QR of RTRI, Vol. 43, No. 3, 2002.

9) Miwa, M.: "Mathematical Programming Model Analysis for the Optimal Track Maintenance Schedule," QR of RTRI, Vol. 43, No. 3, 2002.

10) Ando, K., Mukai, A., Horiike, T., Sunaga, Y., Takao, K., Kito, A.: "Development of Solid-Bed Track with Removable Resilient Ties," QR of RTRI, Vol. 43, No. $3,2002$.

11) Nozawa H.: "Environmental Management System in Railway," Proceeding of the WCRR, Jan. 2002. (CDROM) 